\title{
The Influence of High Academic Achievers' Social Media Usage and Types of Social Media Content on Students' Learning: A Conceptual Framework
}

\author{
Norlaile Salleh Hudin 1,*, Noraine Salleh Hudin², Nor Azah Abdul Aziz ${ }^{3}$ \\ ${ }^{1}$ Faculty of Management and Economics, Sultan Idris Education University, Malaysia \\ ${ }^{2}$ Faculty of Science and Mathematics, Sultan Idris Education University, Malaysia \\ ${ }^{3}$ Faculty of Art, Computing and Creative Industry, Sultan Idris Education University, Malaysia
}

Received July 10, 2019; Revised January 10, 2020; Accepted February 25, 2020

Copyright $\mathrm{C} 2020$ by authors, all rights reserved. Authors agree that this article remains permanently open access under the terms of the Creative Commons Attribution License 4.0 International License

\begin{abstract}
Social media has been blamed for distracting and reducing students' engagement in learning. However, there are limited studies that recommend the appropriate strategy of using social media for students. Therefore, the purpose of this study is to propose a conceptual framework that linked the influence of high academic achievers' social media usage with types of social media content on students' learning. A qualitative methodology will be employed to gain in-depth understanding of the high academic achievers' purpose of using social media, time spent on social media and types of social media contents that interest them. Based on purposive sampling technique, a sample of high academic achievers pursuing their study in a public university will be selected and interviewed until the data reach saturation. The interview data will be analyzed by using thematic analysis to develop codes and themes in explaining the phenomenon. The findings of this study are believed to be useful in developing a recommendation and effective strategy to help students manage their social media usage and more importantly benefit from it for their learning.
\end{abstract}

Keywords Social Media Usage, High Academic Achiever, Social Media Content, Learning Experience

\section{Introduction}

In the era of Education 4.0, incorporating technology in the classroom is essential to help the Millennial cope with the social and academic challenges of students' lives. Social media, for example, Facebook, Instagram, Whatsapp, Telegram and Twitter, are readily available platforms typically used by course instructors to communicate with the students. By using social media, students can receive 24 hours online tutoring, access academic materials anytime and anywhere, receive feedback on their performance continuously and enhance students' collaboration. Nevertheless, evidence showed that despite the awareness of social media usefulness towards academic-related purposes, the actual use of social media for learning was at a minimal level (Sobaih, Moustafa, Ghandforoush, \& Khan, 2016).

Examining the reasons behind this, it was found that excessive use of social media can affect students' academic performance negatively (W. W. F. Lau, 2017; Owusu-Acheaw \& Larson, 2015). Students usually used Facebook for communication, entertainment, and sharing news, pictures and songs (Kaya \& Bicen, 2016). In research conducted in Ghana, most respondents used social media namely Whatsapp and Facebook to make friends or chat (Mingle \& Adams, 2015). Meanwhile, in Spain, students frequently send messages, participate in social networks and listen to music (Carbonell, Chamarro, Oberst, Rodrigo, \& Prades, 2018). As a result, the majority of respondents experienced negative effects such as poor grammar and spelling, late submission of assignments, less study time and poor academic performance due to the heavy participation in social media networks (Mingle \& Adams, 2015). It also lowered their task performance and level of happiness, as well as increased the level of technostress (Brooks, 2015).

In recent times, the majority of students in higher education institutions have smartphones that get them connected to social media. Easy access to social media and the availability of the internet ensure that students have unlimited opportunities to get engaged in social media. However, high academic achievers also have the same exposure towards social media as other students but 
interestingly, they were not distracted and did not decrease their academic performance. Assuming the medical students as high academic achievers, a study on medical students showed that pressure from academic studies motivated them to use social media and support each other (Hartnup, Dong, \& Eisingerich, 2018). Moreover, high academic achievers were underrepresented in the existing literature which mainly focuses on undergraduate students, for example, the works by Whelan, Islam and Brooks (2020), Lau (2017) and Khan, Kend and Robertson (2016). Based on this argument, this research will be conducted to propose a conceptual framework that linked the influence of high academic achievers' social media usage with types of social media content on students' learning.

\section{Literature Review}

\subsection{Social Media}

Social media have been defined as the internet-based channels that allow users to opportunistically interact and selectively self-present, either in real-time or asynchronously, with both broad and narrow audiences who derive value from user-generated content and the perception of interaction with others (Obar \& Wildman, 2015). Based on this definition, social media allow students to make use of them for a variety of purposes not just limited to academic matter. In the real world, students have to present their true personality and appearance, but in social media, they can autonomously create their own identity and become anyone that they dream of. This flexibility can be advantageous and dangerous at the same time. On the one hand, students can seek help from online teachers anonymously according to his/her learning style preferences. Some students prefer to study at night in his comfort room compared to attend lectures while others may prefer to have traditional lectures with a course instructor but revise lessons after class hours. On the other hand, having broad audiences provides students with opportunities to get to know many kinds of people online. The overuse of social media for such leisure activities can distract students from their original roles.

\subsection{Social Media Usage}

Research on Chinese students pursuing their studies abroad revealed that students used social media to increase adaptation (Forbush \& Foucault-Welles, 2016). Having a life-changing venture, social media were used by these students to understand more about foreign cultures even before they step into classrooms. In contrast, students rated sharing documents, information, and opinion, as well as entertainment as the top reasons for using social media in the educational context (Tezci \& İçen, 2017). A qualitative study further exposed that students were motivated to use social media in education mainly for social interaction and feelings of integration (Neier \& Zayer, 2015). Shy students were more inclined to share their opinions through social media compared to face-to-face interaction (Neier \& Zayer, 2015). Certain social media offer students to develop a professional network, however, they are least likely to do so (Knight-McCord et al., 2016).

In terms of time spent on social media, research among students in Saudi Arabia revealed that students generally over the week do not use social media excessively (Alwagait, Shahzad, \& Alim, 2015). Students in Istanbul use social media for 1 to 3 hours daily (Tezci \& İçen, 2017). $40.2 \%$ of Jordanian students spent 1 to 3 hours on social media and $38.5 \%$ spent more than 3 hours on social media (Maqableh et al., 2015). Whereas in Malaysia, students logged into Facebook between 2 to 5 times a day and spent over 60 minutes online daily (Balakrishnan \& Shamim, 2013). Another research found that $41.5 \%$ of Malaysian students used social media 4 to 5 hours per day and $13.9 \%$ used more than 5 hours per day (Ali, Raja, Nuri Al Amin, \& Iftikhar, 2017). Students used 1 to 10 hours on social networking sites each day (Knight-McCord, et al., 2016).

Based on prior researches, it became evident that there were contradictory findings of the purpose and time a student could spend on social media. Avoiding the use of social media does not provide a practical solution for this problem because the benefits of social media are also irrefutable. For example, students' support had been found to increase students' academic achievement (Siti Syamimi Ismail \& Zuraidah Zainol, 2017), and having social media as a student's support platform would magnify the benefits. Despite that, less study has been conducted to explore the use of social media among high academic achievers. For that reason, it seems too early to recommend the appropriate measure on how students should be involved in social media without gaining more information on how high academic achievers find the right balance between their social media usage and learning.

\subsection{Types of Social Media Content}

There are three categories related to 12 themes of Facebook postings (Klein, Niebuhr, \& D'Alessandro, 2013) as shown in Table 1 . The first category is peer learning which represents the use of social media to accomplish a set of learning. In the context of this research, it can occur when the research participants use their social media to find someone with the same assignment, and ignite a conversation about their ideas or gain others' opinions about a topic. The second category is building rapport, support, and community which refers to sharing advice on how to complete a task and comforting others emotionally by giving positive comments, asking how others' feelings and conditions as well as expressing gratitude to others who helped. The last category of Facebook post is technical 
aspects which are related to technical issues in Facebook usage such as hitting a button too soon or privacy setting of a post.

Table 1. Types of Facebook posts

\begin{tabular}{|c|c|}
\hline Category & Theme \\
\hline Peer learning (learning capital) & $\begin{array}{c}\text { Assignments } \\
\text { Acknowledgement of common } \\
\text { goals } \\
\text { Steering group back to another } \\
\text { post } \\
\text { Questions } \\
\text { Shared learning } \\
\end{array}$ \\
\hline $\begin{array}{l}\text { Rapport, support, and } \\
\text { community building } \\
\text { (social capital) }\end{array}$ & $\begin{array}{c}\text { Asking for help } \\
\text { Offering advice and help } \\
\text { Cheerleading and validation } \\
\text { Compliments } \\
\text { Gratitude } \\
\text { Social conversations }\end{array}$ \\
\hline Technical aspects & Technical difficulties \\
\hline
\end{tabular}

Source: (Klein, et al., 2013)

Another research listed two types of social media posts, namely community news and inspiring messages (Joo, Choi, \& Baek, 2018). Emotionally inspiring messages, community news, and posts having an image had a higher engagement from users (Joo, et al., 2018). Besides, male users were found to engage more in posts containing reasoning and analysis, and quotes from famous people and sources while females had a higher engagement in posts containing quotes from people or other sources (Savage, Monroy-Hernandez, Singer, \& Hollerer, 2013).

There is yet research conducted to explore how social media contents are related to learning experiences, particularly in an educational context. For millennial students, they are exposed to more social media content for a long period, thus certain types of social media content could influence how they learn without affecting their academic performance. Therefore, understanding the types of social media contents that interest these high academic achievers seems relevant to increase students ' performance in general.

\section{Methodology/Materials}

This research will use a qualitative research design to explore high academic achievers' social media usage and learning. Previous studies inter alia Lau (2017), Brown,
Adams, Browne and Arrastia-Chisholm (2018), Boahene, Fang and Sampong (2019), and Amir, Hussain, Hussain and Hashmat (2016) embarked on the quantitative methodology which limits in-depth understanding of the phenomenon based on research participants' living experience. The study will be conducted at one of the public universities in Malaysia whereby the students will be selected based on a purposive sampling technique. The criteria for sample selection are as follows:

- Final year students in pure science and social science programs

- $\quad$ Obtaining minimum 3.7 in CGPA

- $\quad$ Possessing good communication skill

- Willingness to participate in the study

The number of participants will be determined by the saturation of the data (Ness, 2015). The interview protocol will be verified by two experts in the education field to ensure that the wording of the open-ended questions is suitable and correct. In the meantime, participants will be contacted to obtain their informed consent and arrange the interview sessions. The interview protocol contains four parts. Part A aims to build rapport and trust with the participants. Questions about their education and family background, as well as their learning preferences will be asked. In Part B, participants will be asked to elaborate on their social media usage. Particularly, data about participants' purpose of using social media and usage time will be gathered. In Part C, participants will be inquired to explain the types of social media contents which interest them. Finally in Part D, participants' learning experiences, particularly the influence of social media towards their learning, will be explored.

After data collection, framework analysis adopted from Srivastava and Thomson (2009) as shown in Figure 1 will be used. First, researchers will transcribe the interview recordings verbatim and familiarize with the data to identify major ideas. Next, the thematic analysis suggested by LeCompte (2000) will be performed where transcripts will be coded and then categorized into themes. The themes will be generated based on the frequency of response, omission or declaration of a statement by the participants. A new theme may also emerge at the later stage of the process, and researchers will reconstruct the themes again. In the final stage, a global theme will emerge along with sub-themes in a chart to describe the phenomenon under this study. 


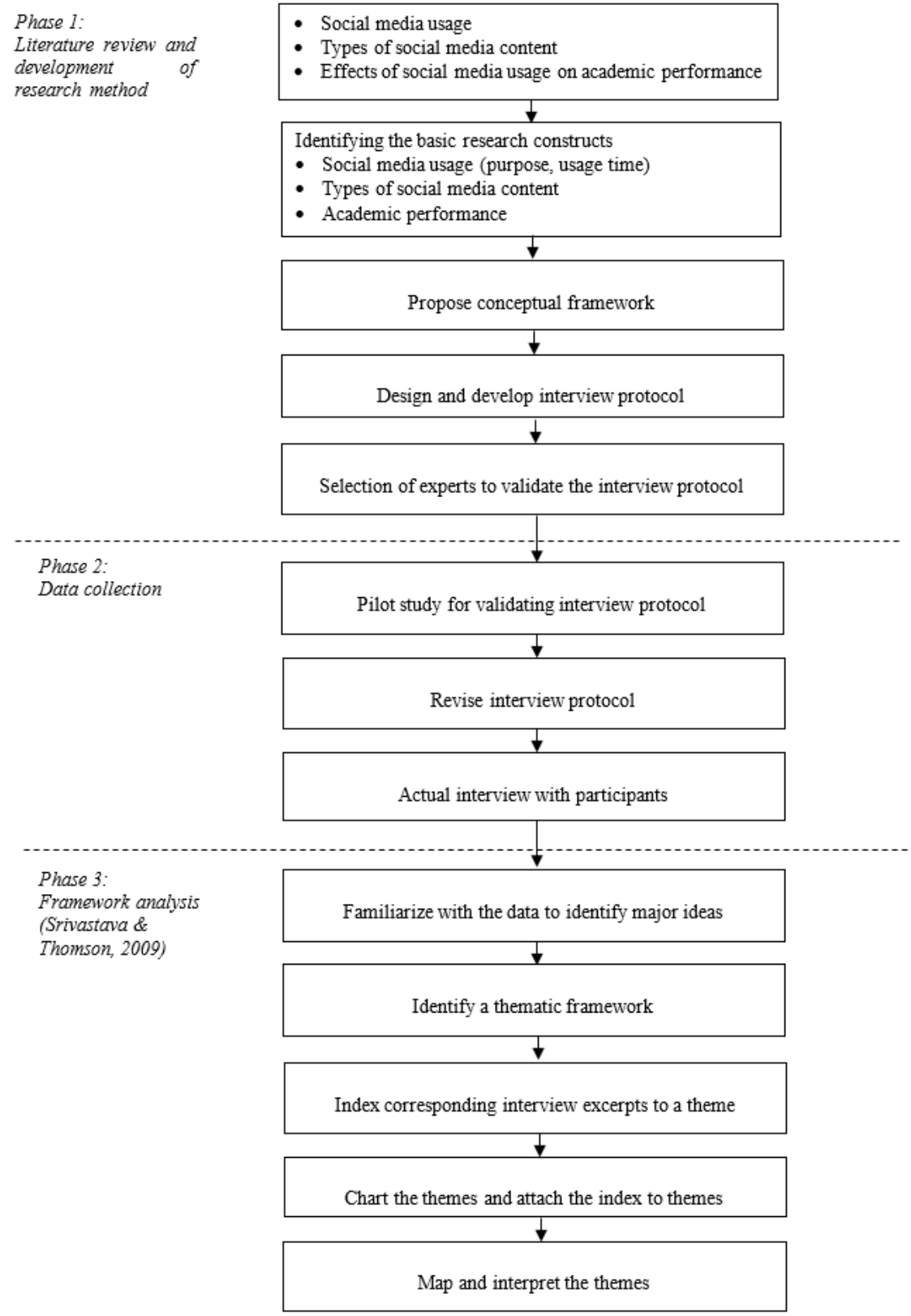

Figure 1. Overall structure of research method

\section{Research Framework}

Figure 2 displays the links between social media usage, types of social media content and learning experiences. Based on this framework, the researcher aims to explore the purpose of high academic achievers' social media usage and how often they use it either for study, recreation or any other purposes. The social media contents that these students view will also be explored to understand how social media are related to their learning experiences. 


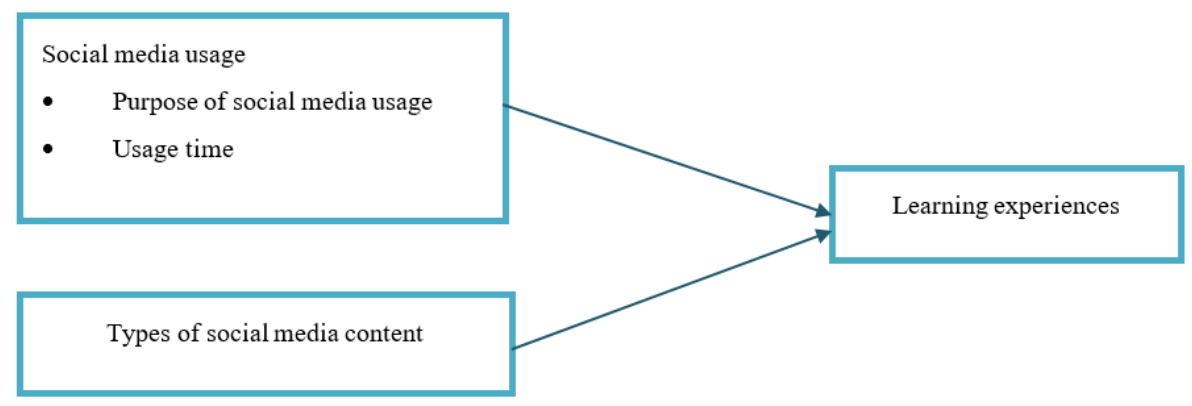

Figure 2. Research framework

\section{Conclusions}

This research aims to propose a framework of high academic achievers' social media usage, types of social media content and their experiences towards learning. A qualitative research design will be employed with a sample of purposely selected high academic achievers from a public university in Malaysia. The findings of this research will provide some preliminary understanding of social media and the learning experiences of high academic achievers in Malaysia. It is believed that students' learning experiences are influenced by the purpose of social media usage, time spent on social media and types of social media content. By exploring this situation, a recommendation can be proposed and effective strategies can be developed to help students manage their social media usage and more importantly benefit from it for their learning.

\section{Acknowledgements}

This research is funded by Universiti Pendidikan Sultan Idris Research Grant (2018-0024-107-01).

\section{REFERENCES}

[1] Ali, Murad, Raja, Raja Ahmad Iskandar B, Nuri Al Amin, B Endut, \& Iftikhar, Bilal. (2017). Determining the academic Use of Social Media with Technology Acceptance Models. NFC IEFR Journal of Engineering and Scientific Research, 5 .

[2] Alwagait, Esam, Shahzad, Basit, \& Alim, Sophia. (2015). Impact of social media usage on students academic performance in Saudi Arabia. Computers in human behavior, 51, 1092-1097. doi: https://doi.org/10.1016/j.chb.2014.09.028

[3] Amin, Zahid, Mansoor, Ahmad, Hussain, Syed Rabeet, \& Hashmat, Faisal. (2016). Impact of social media of student's academic performance. International Journal of Business and Management Invention, 5(4), 22-29.

[4] Balakrishnan, Vimala, \& Shamim, Azra. (2013). Malaysian Facebookers: Motives and addictive behaviours unraveled.
Computers in human behavior, 29(4), 1342-1349.

[5] Barton, Bianca A, Adams, Katharine S, Browne, Blaine L, \& Arrastia-Chisholm, Meagan C. (2018). The effects of social media usage on attention, motivation, and academic performance. Active Learning in Higher Education, 1469787418782817.

[6] Boahene, Kingsley Osei, Fang, Jiaming, \& Sampong, Frank. (2019). Social Media Usage and Tertiary Students' Academic Performance: Examining the Influences of Academic Self-Efficacy and Innovation Characteristics. Sustainability, 11(8), 2431.

[7] Brooks, Stoney. (2015). Does personal social media usage affect efficiency and well-being? Computers in human behavior, 46, 26-37. doi: https://doi.org/10.1016/j.chb.201 4.12.053

[8] Carbonell, Xavier, Chamarro, Andrés, Oberst, Ursula, Rodrigo, Beatriz, \& Prades, Mariona. (2018). Problematic use of the internet and smartphones in university students: 2006-2017. International journal of environmental research and public health, 15(3), 475.

[9] Forbush, Eric, \& Foucault-Welles, Brooke. (2016). Social media use and adaptation among Chinese students beginning to study in the United States. International Journal of Intercultural Relations, 50, 1-12.

[10] Hartnup, Becky, Dong, Lin, \& Eisingerich, Andreas Benedikt. (2018). How an environment of stress and social risk shapes student engagement with social media as potential digital learning platforms: qualitative study. JMIR medical education, 4(2), e10069.

[11] Joo, Soohyung, Choi, Namjoo, \& Baek, Tae Hyun. (2018). Library marketing via social media: The relationships between Facebook content and user engagement in public libraries. Online Information Review, 42(6), 940-955. doi: doi:10.1108/OIR-10-2017-0288

[12] Kaya, Tugberk, \& Bicen, Huseyin. (2016). The effects of social media on students' behaviors; Facebook as a case study. Computers in human behavior, 59, 374-379. doi: https://doi.org/10.1016/j.chb.2016.02.036

[13] Khan, Tehmina, Kend, Michael, \& Robertson, Susan. (2016). Use of social media by university accounting students and its impact on learning outcomes. Accounting Education, 25(6), 534-567.

[14] Klein, Melissa, Niebuhr, Virginia, \& D'Alessandro, Donna. (2013). Innovative Online Faculty Development Utilizing 
the Power of Social Media. Academic Pediatrics, 13(6), 564-569. doi: https://doi.org/10.1016/j.acap.2013.07.005

[15] Knight-McCord, Jasmine, Cleary, Dylan, Grant, Nastassjia, Herron, Antoinette, Lacey, T, Livingston, T, \& Emanuel, R. (2016). What social media sites do college students use most. Journal of Undergraduate Ethnic Minority Psychology, 2(21), 21-26.

[16] Lau, Wilfred W. F. (2017). Effects of social media usage and social media multitasking on the academic performance of university students. Computers in human behavior, 68, 286-291. doi: https://doi.org/10.1016/j.chb.2016.11.043

[17] Lau, Wilfred WF. (2017). Effects of social media usage and social media multitasking on the academic performance of university students. Computers in human behavior, 68, 286-291.

[18] LeCompte, Margaret D. (2000). Analyzing qualitative data. Theory into practice, 39(3), 146-154.

[19] Maqableh, Mahmoud, Rajab, Lama, Quteshat, Walaa, Masa'deh, Ra'ed MT, Khatib, Tahani, \& Karajeh, Huda. (2015). The impact of social media networks websites usage on students' academic performance.

[20] Mingle, Jeffrey, \& Adams, Musah. (2015). Social media network participation and academic performance in senior high schools in Ghana. Library Philosophy and Practice, 1.

[21] Neier, Stacy, \& Zayer, Linda Tuncay. (2015). Students' perceptions and experiences of social media in higher education. Journal of Marketing Education, 37(3), 133-143.

[22] Ness, Lawrence R. (2015). Are we there yet? Data saturation in qualitative research.

[23] Obar, Jonathan A, \& Wildman, Steven S. (2015). Social media definition and the governance challenge-an introduction to the special issue. Obar, JA and Wildman, S.(2015). Social media definition and the governance challenge: An introduction to the special issue. Telecommunications policy, 39(9), 745-750.

[24] Owusu-Acheaw, M, \& Larson, Agatha Gifty. (2015). Use of Social Media and Its Impact on Academic Performance of Tertiary Institution Students: A Study of Students of Koforidua Polytechnic, Ghana. Journal of Education and Practice, 6(6), 94-101.

[25] Savage, Saiph, Monroy-Hernandez, Andres, Singer, Leif, \& Hollerer, Tobias. (2013). Say My Name, Say My Name: User Mentioning on Facebook. GSWC 2013, 39.

[26] Siti Syamimi Ismail, \& Zuraidah Zainol. (2017). The efffect of authoritative school climate on students' academic achievement. International Business Education Journal, $10(1), 8-16$

[27] Sobaih, Abu Elnasr E, Moustafa, Mohamed A, Ghandforoush, Parvis, \& Khan, Mahmood. (2016). To use or not to use? Social media in higher education in developing countries. Computers in human behavior, 58, 296-305.

[28] Srivastava, Aashish, \& Thomson, S Bruce. (2009). Framework analysis: a qualitative methodology for applied policy research.

[29] Tezci, Erdogan, \& İçen, Mustafa. (2017). High School
Students' Social Media Usage Habits. Online Submission, 8(27), 99-108.

[30] Whelan, Eoin, Islam, AKM Najmul, \& Brooks, Stoney. (2020). Applying the SOBC paradigm to explain how social media overload affects academic performance. Computers \& Education, 143, 103692. 